\title{
ARTICLE OPEN Flexible, transparent nanocellulose paper-based perovskite solar cells
}

\author{
Lei Gao ${ }^{1}$, Lingfeng Chao ${ }^{1}$, Meihui Hou ${ }^{1}$, Jin Liang ${ }^{1}$, Yonghua Chen ${ }^{1}$, Hai-Dong Yu $\mathbb{D}^{1}$ and Wei Huang ${ }^{1,2}$
}

Recently perovskite solar cells (PSCs), as photoelectric conversion devices, exhibit excellent power conversion efficiency (PCE) and low-processing cost, and have become one of the most promising devices to replace conventional silicon-based solar cells and address current pressing energy issues. Among them, the flexible PSCs are especially more widely applicable and may propel the rapid advancements of wearable electronics, causing a significant paradigm shift in consumer electronics. Current flexible PSCs use non-biodegradable petroleum-based polymer substrates, discarding of which will aggravate "white pollution". Therefore, development of green, biodegradable and low-cost flexible substrates will provide a great alternative to flexible PSCs. Here we have developed transparent nanocellulose paper (NCP) with coating of acrylic resin as substrates to fabricate flexible PSCs, which are biodegradable and easily disposable. The PCE of these NCP-based PSCs reached $4.25 \%$, while the power per weight (the ratio of power to device weight) was as high as $0.56 \mathrm{~W} \mathrm{~g}^{-1}$. The flexible PSCs also showed good stability, retaining $>80 \%$ of original efficiency after 50 times of bending. The NCP-based substrates can also be applied to other electronic systems, which may prosper next-generation green flexible electronics.

npj Flexible Electronics (2019)3:4; https://doi.org/10.1038/s41528-019-0048-2

\section{INTRODUCTION}

Developing renewable energy sources has become an increasingly urgent task due to the depletion of fossil fuel supply and the growth of energy demand. " Solar energy, inexhaustible and clean without any pollution, has become one of the most potential avenues of renewable energy ${ }^{2}$ and photovoltaic technology that converts solar energy to electrical energy has been considered as the most promising strategy to address the ever-increasing energy issues. ${ }^{3}$ Recently perovskite solar cells (PSCs), a new type of solar cells based on mixed organic-inorganic halide perovskites, have rapidly attracted vast attention and gradually become one of the most important all-solid-state solar cells. In the past few years, the power conversion efficiency (PCE) of organic-inorganic hybrid PSCs has increased from 3 to $23.3 \%,{ }^{4}$ (https://www.nrel.gov/pv/ assets/images/efficiency-chart.png) which is currently comparable to that of commercialized silicon-based solar cells, while the cost of the PSCs can be much lower due to their convenient fabrication process. More importantly, the flexible PSCs are expected to have broad potential applications, including wearable or portable electronics, sun-powered vehicles, unmanned airplanes, and so on. ${ }^{5-7}$ However, films of polyethylene terephthalate (PET) and polyethylene naphthalate (PEN) coated with ITO are most widely used as substrates for flexible $\mathrm{PSCs}^{7}$ which are not easily degraded and may lead to "white pollution"-serious environmental concerns caused by inapposite discarding of petroleumbased polymers. ${ }^{8}$ For example, the garbage island floating in the Pacific, which was made of at least 4 million tons non-degradable plastic wastes, will threaten the environment, maritime safety, marine lives, and even human life; ${ }^{9}$ disposal of these nondegradable plastic wastes may generate charred residue solid ash, black airborne particulate smoke, inhalable airborne particles, and toxic heavy metals. ${ }^{10}$ Thus, the use of biodegradable materials and substrates in flexible electronics would reduce the accumulation of persistent solid waste, thereby benefiting our living environment. ${ }^{11}$

Paper has been developed for more than 2000 years in daily life. As a flexible, biodegradable, cheap, abundant, lightweight, easily available, and environmentally friendly material, cellulose-based paper has attracted growing interest in the research community for building flexible electronics. ${ }^{13-18}$ When using paper as a conductive substrate, high surface roughness is usually unfavorable because of its inversely proportional relationship with conductivity. ${ }^{18}$ Opaque paper with smooth surface has been specially designed for preparing PSCs as flexible substrate. ${ }^{19}$ However, to further simplify the preparation process and improve the PCE of PSCs, it is still in imperative demands to develop transparent substrates for building PSCs.

The nanocellulose paper (NCP), made from wood, cotton, and other cellulose-rich materials ${ }^{20,21}$ by mechanical method ${ }^{22}$ or chemical dissolving, ${ }^{23}$ exhibits excellent features as flexible substrate for optoelectronic devices, such as appropriate mechanical strength, thermal and chemical stability, and, in particular, high transparency and low surface roughness. ${ }^{24}$ It is also biodegradable, eco-friendly and can be easily disposed as same as the traditional paper. The use of NCP as flexible substrate in printed electronics has shown promising prospect, for instance, transparent conductive electrode ${ }^{25}$ electroluminescent device, ${ }^{26}$ supercapacitor, ${ }^{27,28}$ touch screen, ${ }^{29}$ organic solar cells, ${ }^{30}$ organic light emitting diodes, ${ }^{31}$ conductive lines, ${ }^{32,33}$ and transistors. ${ }^{34}$ Unfortunately, one of the main obstacles for using NCP as flexible

\footnotetext{
${ }^{1}$ Institute of Advanced Materials (IAM) \& Key Laboratory of Flexible Electronics (KLOFE), Jiangsu National Synergetic Innovation Center for Advanced Materials (SICAM), Nanjing

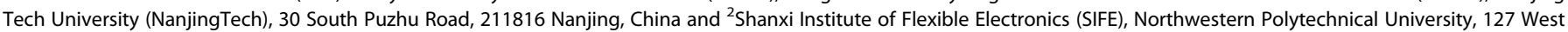
Youyi Road, 710072 Xi'an, China

Correspondence: Yonghua Chen (iamyhchen@njtech.edu.cn) or H-D. Yu (iamhdyu@njtech.edu.cn) or Wei Huang (iamwhuang@njtech.edu.cn)
}

Received: 2 September 2018 Accepted: 3 January 2019

Published online: 11 February 2019 


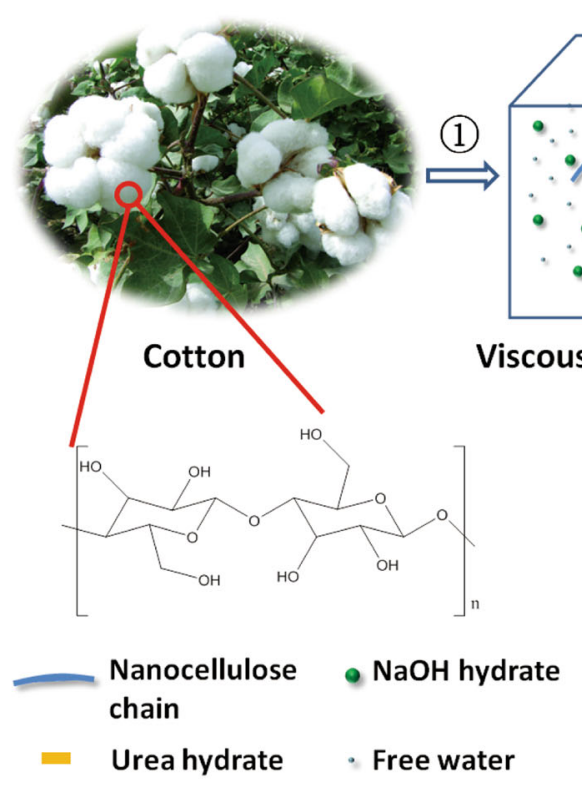

Channel inclusion compound

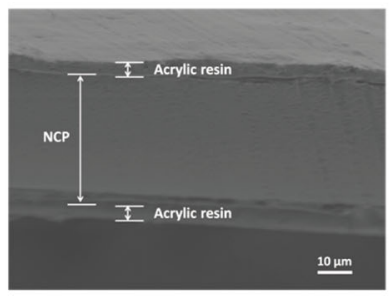

$\underline{10 \mu \mathrm{m}}$

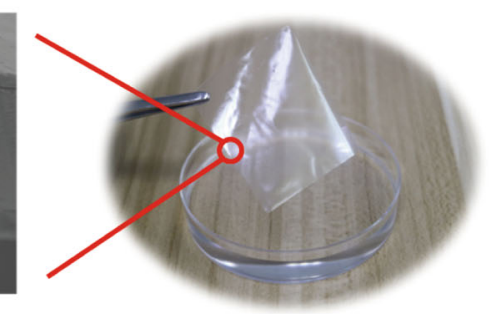

NCP-based substrate

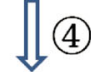

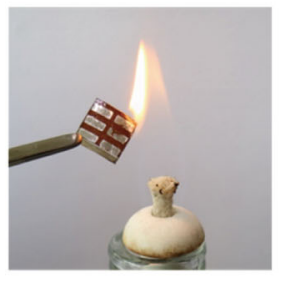

Disposing

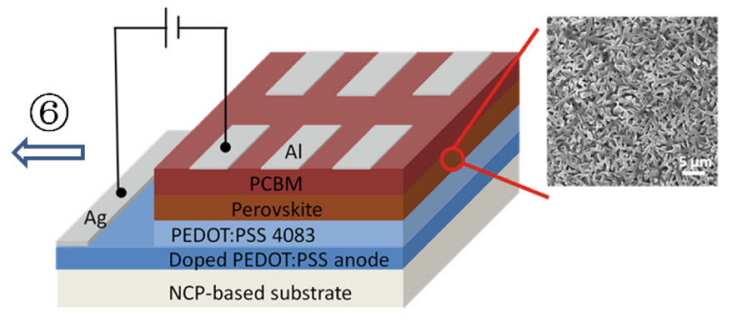

NCP-based PSCs

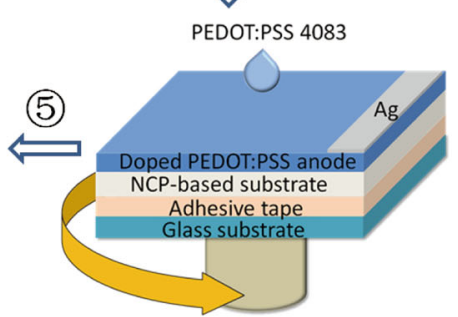

Preparation of PSCs

Fig. 1 Preparation process of NCP-based substrate and NCP-based PSCs. (1) The nanocellulose was extracted from cotton to form viscous solution. (2) NCP was made from viscous solution of nanocellulose. (3) NCP was coated by acrylic resin to form waterproof layer on its surface. $(4,5)$ The preparation of NCP-based PSCs. (6) Flexible PSCs can be disposed easily by flame burning

substrate is its poor shape stability in water or other solution, ${ }^{35}$ which makes it unsuitable as substrate for PSCs, especially through a fully solution-processed method.

Here, we have developed NCP-based flexible PSCs for the first time. We have coated NCP with acrylic resin to make it waterproof and suitable as substrate for solution-processed PSCs. The PCE of NCP-based PSCs was $4.25 \%$ with the power per weight up to $0.56 \mathrm{~W} \mathrm{~g}^{-1}$. These flexible PSCs exhibited good stability, retaining $>80 \%$ of original efficiency after 50 times of bending with a curvature diameter of $15 \mathrm{~mm}$. The NCP-based PSCs are biodegradable and can be easily disposed (e.g., by flame burning within $3 \mathrm{~s}$ ), showing the great potential of NCP as substrates for green flexible electronics. The NCP-based PSCs provide a flexible renewable energy device without adverse environmental effects, and suggest a new pathway for making other low-cost, transparent, and eco-friendly flexible electronics.

\section{RESULTS AND DISCUSSION}

The recyclable illustration of NCP-based PSCs

Figure 1 shows the preparation process of NCP-based PSCs, which presents its likely recyclable illustration. Firstly, NCP was made from viscous solution of nanocellulose of natural cotton ${ }^{21}$ and coated by acrylic resin to form waterproof layer on its surface (step 1-3 of Fig. 1). Cotton, as a cellulose-rich low-cost material, was chosen as raw material to fabricate NCP. It is noted that the asfabricated pure NCP was vulnerable to water and became seriously wrinkled due to the swelling of nanocellulose, which is unfavorable as substrate for flexible electronics, especially flexible PSCs prepared by a fully solution-processed method (e.g., PEDOT: PSS is a water-based reagent). To solve this problem, we coated pure NCP with acrylic resin, a type of plastic usually used in electronics due to its eco-friendly, low-cost, easy-to-handle, highly transparent properties, and appropriate mechanical strength, thermal stability, low surface roughness, and especially excellent waterproof ability. The coating of acrylic resin formed a protective layer on the surface of NCP to protect NCP from water and improved the properties of NCP including transmittance, tensile strength and thermal stability. This treatment allowed for easier handling and manufacturing abilities of NCP-based substrate for subsequent fabrication of flexible PSCs.

Secondly, flexible PSCs were prepared on the NCP-based substrate (step 4-5 of Fig. 1). NCP-based substrate retained stable shape in water so that we could use a typical fully solutionprocessed method to build PSCS. PEDOT:PSS (PH1000) doped with Triton-X 100 and ethylene glycol was used to fabricate transparent conductive anode on NCP-based substrate by a spin-coating method. The other functional layers including hole transport layer (PEDOT:PSS 4083), photoelectric active layer (perovskite layer) and 
(a)

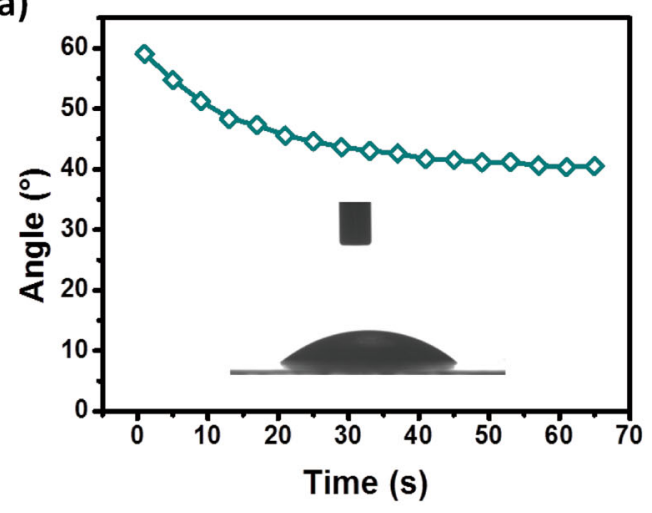

(c)

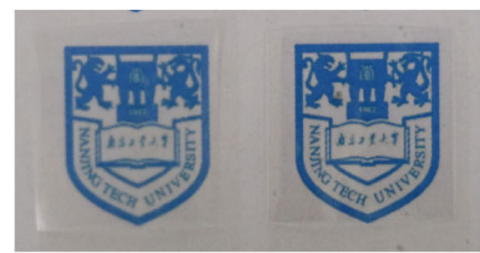

(b)

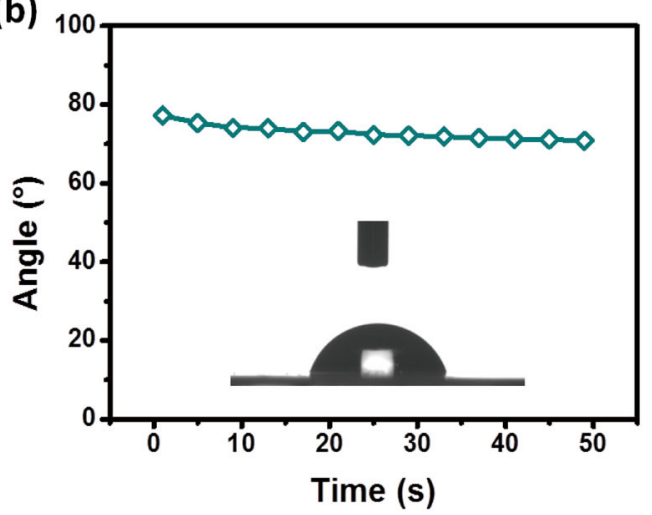

(e) (d)

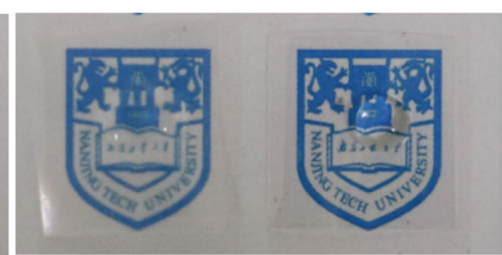

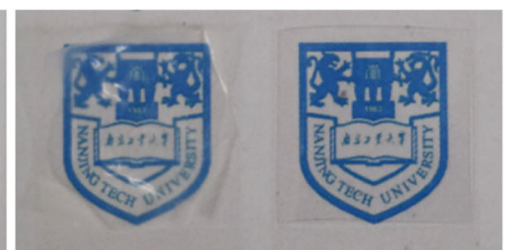

Fig. 2 Contact angle measurement and water-drop test. The contact angle measurement with water of a NCP and $\mathbf{b}$ NCP-based substrate with coating of acrylic resin. Digital photographs of (left) NCP and (right) NCP-based substrate $\mathbf{c}$ before dropping water, $\mathbf{d}$ after dropping water and e after drying thoroughly

electron transport layer (PCBM) were constructed by the same spin-coating method.

After usage, flexible PSCs can be disposed easily by flame burning, generating little environmental pollution (step 6 of Fig. 1). Because the substrate is a type of cellulose-rich materials, only carbon dioxide and carbon materials were produced from the substrate when the NCP-based PSCs were disposed by flame burning. As for the functional layers of the NCP-based PSCs, their mass fraction was less than $34 \%$ of the whole device, which is low as compared to that of the substrate (over $66 \%$ of the device), and thus disposal of these functional layers generated little environmental pollution. Finally, the burnt ashes of the NCP-based PSCS could be sent back to natural soil as fertilizer of cotton or other plants to accomplish the green cycle.

\section{Waterproof capacity of NCP-based substrate}

To make the NCP waterproof as substrate for flexible PSCs, we have coated pure NCP with a layer of acrylic resin. The thickness of acrylic resin and NCP is about $3.5 \mu \mathrm{m}$ and $40 \mu \mathrm{m}$, respectively (Supplementary Fig. 6a), while the weight of $1 \mathrm{~cm}^{2}$ substrates without and with acrylic resin is $3.31 \mathrm{mg}$ and $4.96 \mathrm{mg}$, respectively (Supplementary Fig. 6b). Contact angle measurement and waterdrop test have shown the excellent waterproof capacity of NCPbased substrate (Fig. 2). During the contact angle measurement, the contact angle of water on pure NCP decreased from $59^{\circ}$ to $40^{\circ}$ over $65 \mathrm{~s}$ (Fig. 2a). After $40 \mathrm{~s}$, the contact angle reached $\sim 40^{\circ}$ and kept stable. The reason for descending of the contact angle is that pure NCP absorbed certain amount of water before $40 \mathrm{~s}$ due to its swelling property, enhancing hydrophilic ability of NCP. After that, the content of water reached maximum in pure NCP and the contact angle of water kept stable on pure NCP. As for the NCPbased substrate with coating of acrylic resin, the contact angle of water kept stable at $\sim 71^{\circ}$ over $50 \mathrm{~s}$ (Fig. 2b), which was the same as pure acrylic resin film (Supplementary Fig. 1). The cellulosebased NCP is more hydrophilic than acrylic resin and has shown a lower value of the contact angle of water. Stable contact angle of water on NCP-based substrate as compared to that of pure NCP implies that a protective layer of acrylic resin has been successfully formed on the surface of NCP and water cannot permeate into inner NCP, exhibiting excellent waterproof capacity.

For water-drop test, pure NCP and NCP-based substrate with coating of acrylic resin were cut into $2 \times 2 \mathrm{~cm}$ square sheets and put on the top of logo patterns (Fig. 2c). A drop of water $(40 \mu \mathrm{L}$ ) was added on their surfaces (Fig. 2d). Then they were dried naturally at room temperature (Fig. 2e). According to the final dry state, pure NCP deformed severely while the NCP-based substrate was still flat and regular. Swelling process of pure NCP rebuilt inner architecture of nanocellulose chains and led to asymmetric distribution of strain force, resulting in severe deformation of pure $\mathrm{NCP}$; on the other hand, the coating layer of acrylic resin prevented permeation of water into the NCP and protected the NCP to remain a stable shape. The coating layer of acrylic resin not only formed a uniform protective layer on the surface of NCP (Supplementary Fig. 6a), but also improved the flatness of the surface (Supplementary Fig. 2), making the NCP-based substrate excellent for flexible PSCs.

\section{Other properties of NCP-based substrate}

In flexible electronics, transmittance, mechanical properties and thermal stability are vital parameters of the substrates, especially for high-performance photoelectric devices. ${ }^{36}$ Here, we have characterized these properties of NCP-based substrate through UV-Vis, strain-stress and thermal expansion measurements (Fig. 3). The NCP-based substrate has displayed very high transmittance $(>90 \%)$ in visible light wavelength (Fig. 3a). At the wavelength of $550 \mathrm{~nm}$, transmittance of NCP was $90.70 \%$ and transmittance of acrylic resin was $91.79 \%$, while transmittance of the NCP-based substrate with coating of acrylic resin was $91.71 \%$. Especially in wavelength less than $700 \mathrm{~nm}$, NCP-based substrate and acrylic resin revealed higher transmittance than NCP. The reason for this might be that the as-prepared NCP had rough surface due to home-made preparation, which led to a little light scattering. As acrylic resin has higher transmittance than NCP, the coating layer of acrylic resin reduced light scattering and improved luminousness of the NCP-based substrate (see also inset of Fig. 3a). With the coating of acrylic resin, the mean value 
(a)

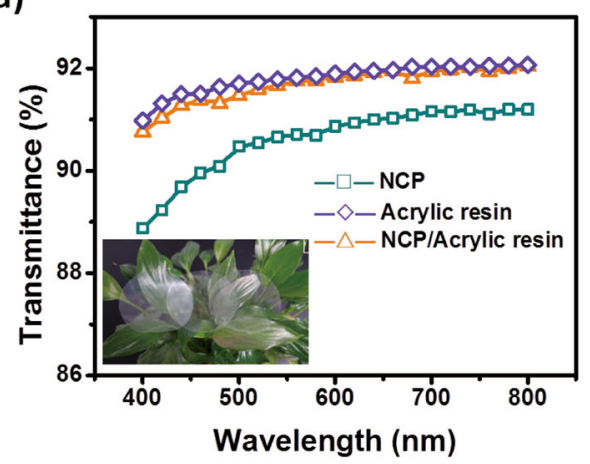

(c)

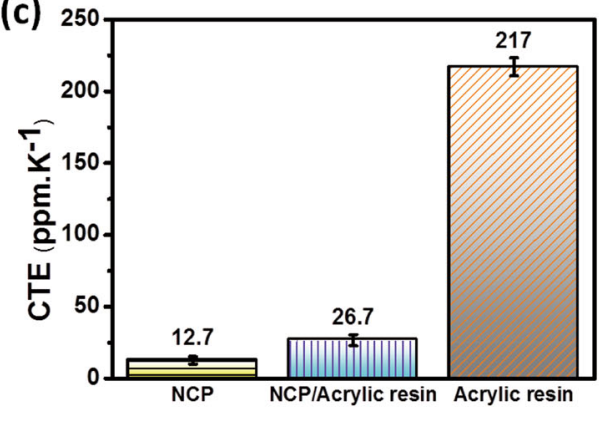

(b)

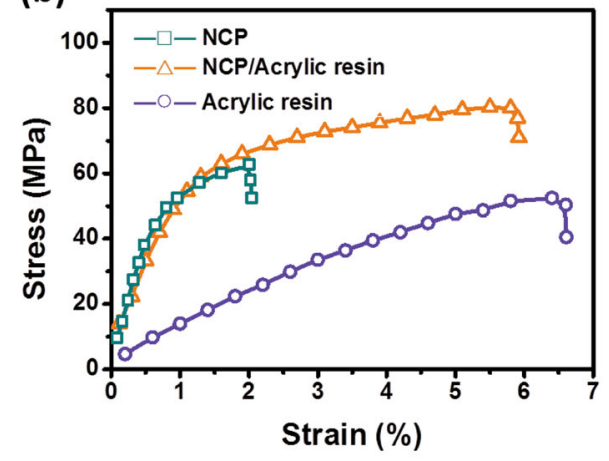

(d)

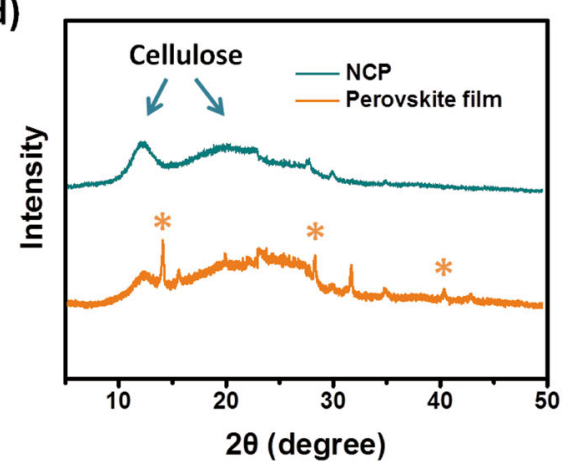

Fig. 3 Comparison of NCP and NCP-based substrate with coating of acrylic resin. a Transmittance, $\mathbf{b}$ strain-stress curve, and $\mathbf{c}$ coefficient of thermal expansion (CTE) of NCP, NCP-based substrate and acrylic resin film. Each data point is the mean of three analyses. Inset: digital photograph of NCP, NCP-based substrate and acrylic resin film from left to right. $\mathbf{d}$ X-Ray diffraction of NCP and flexible PSCs prepared on the NCP-based substrate

of root-mean-square (RMS) surface roughness of NCP decreased from 9.507 to $2.151 \mathrm{~nm}$ (Supplementary Fig. 3), which indicates that the coating layer of acrylic resin can improve not only the transmittance, but also the smoothness of the NCP-based substrate. Better functional layers of PSCs could be built on smooth substrates due to minimal defect on the surface, which is beneficial for charge transport and collection.

The NCP-based substrate has also exhibited excellent mechanical properties. From the strain-stress curve (Fig. 3b), we can see that tensile strength and Young's modulus of pure NCP were $62.8 \mathrm{MPa}$ and $3.5 \mathrm{GPa}$, while those of acrylic resin were $52.5 \mathrm{MPa}$ and $0.8 \mathrm{GPa}$, smaller than those of NCP. Noteworthy, tensile strength and Young's modulus of the NCP-based substrate with coating of acrylic resin were $81 \mathrm{MPa}$ and $4.9 \mathrm{GPa}$, which increased about 28.9 and $40 \%$ compared to NCP (about 54.3 and $512.5 \%$ compared to pure acrylic resin film). When coating acrylic resin on $\mathrm{NCP}$, the solution of acrylic resin was filled into nanostructured architectures of the NCP to form a protecting layer on its surface, resulting in better tensile strength and Young's modulus of NCPbased substrate. It is clear that coating of acrylic resin on NCP has greatly improved its mechanical properties, which offers NCPbased substrate with appropriate mechanical properties for building flexible PSCs.

Finally, the NCP-based substrate has shown outstanding thermal stability. The coefficient of thermal expansion (CTE) of acrylic resin was very high, which reached $217 \mathrm{ppm} \mathrm{K}^{-1}$ (Fig. 3c). Thus the film of acrylic resin experienced large transformation of shape during heating process, which is unfavorable for preparation of flexible electronics, e.g., being annealed at high temperature $\left(>100^{\circ} \mathrm{C}\right)$ during fabrication. On the other hand, pure NCP had low CTE, which was only $12.7 \mathrm{ppm} \mathrm{K}^{-1}$. The CTE of the NCP-based substrate was $26.7 \mathrm{ppm} \mathrm{K}^{-1}$, which is much lower than that of acrylic resin and many other polymers. The low CTE of the NCP-based substrate demonstrates its superb thermal- mechanical property in heating process for fabrication of flexible electronics. Moreover, NCP and NCP-based substrate with coating of acrylic resin exhibited excellent heat resistance as compared to common PET $\left(165^{\circ} \mathrm{C}\right)$, which remained stable up to $310^{\circ} \mathrm{C}$ and $294^{\circ} \mathrm{C}$, respectively (Supplementary Fig. 4). While the coating layer of acrylic resin improved the waterproof capacity, transmittance, smoothness, and mechanical properties of the NCP-based substrate, NCP made the NCP-based substrate have less thermal expansion and better heat resistance. Moreover, both NCP and NCP-based substrate with acrylic resin revealed excellent flexibility, with no cracks observed on the surface of these substrates after 1000 bending cycles (bending angle is $180^{\circ}$ ) (Supplementary Fig. 7).

\section{Performance of NCP-based PSCs}

We have successfully fabricated flexible PSCs on the NCP-based substrate (inset of Fig. 4b). The planar heterojunction PSCs were structured as doped PEDOT:PSS anode $(40 \mathrm{~nm}) / \mathrm{PEDOT}$ :PSS 4083 $(30 \mathrm{~nm}) /$ Perovskite $(350 \mathrm{~nm}) / \mathrm{PCBM}(100 \mathrm{~nm}) / \mathrm{Al}(100 \mathrm{~nm})$ (Fig. 4a). The best-performing device exhibited a PCE of $4.25 \%$, a $V_{\text {oc }}$ of $0.69 \mathrm{~V}$, a $J_{\text {sc }}$ of $17.46 \mathrm{~mA} \mathrm{~cm}^{-2}$, and a FF of $34.65 \%$ with no hysteresis (Fig. 4b, c, Table 1). The high incident photon-toelectron conversion efficiency (IPCE) over the whole visible spectrum confirmed the high current density of $17.68 \mathrm{~mA} \mathrm{~cm}^{-2}$ (Fig. 4d). Good reproducibility was achieved with a typical value of over $3 \%$ for more than $80 \%$ of the devices (Fig. $4 \mathrm{e}$ ). The NCPbased PSCs have presented good stability after 50 times of bending with a curvature diameter of $15 \mathrm{~mm}$, retaining $>80 \%$ of its original efficiency (Fig. 4f). The efficiency decreasing with bending cycles is probably due to the cracks of perovskite layer formed during the bending cycles (Supplementary Fig. 8). These cracks could hinder the mobility of carrier and deteriorate the performance of device. In addition, the reference PSCs without 
(a)

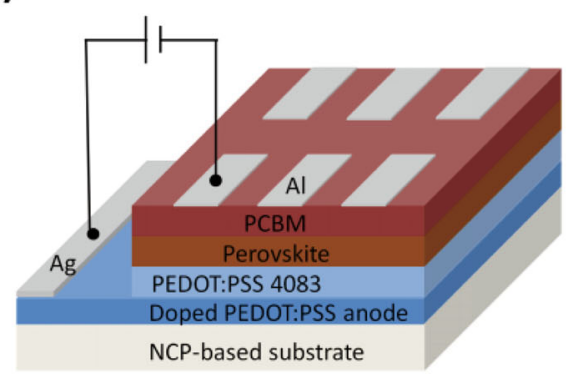

(c)

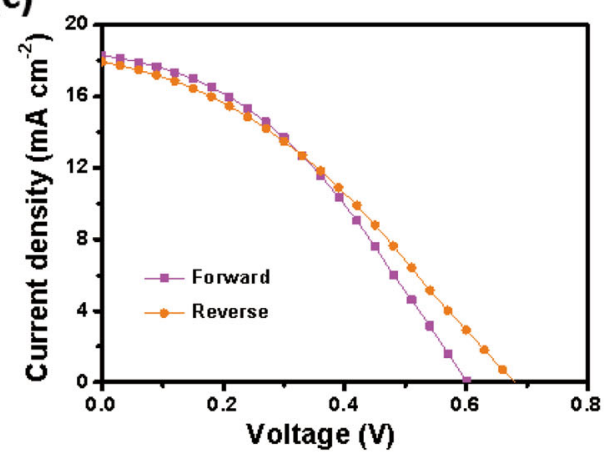

(e)

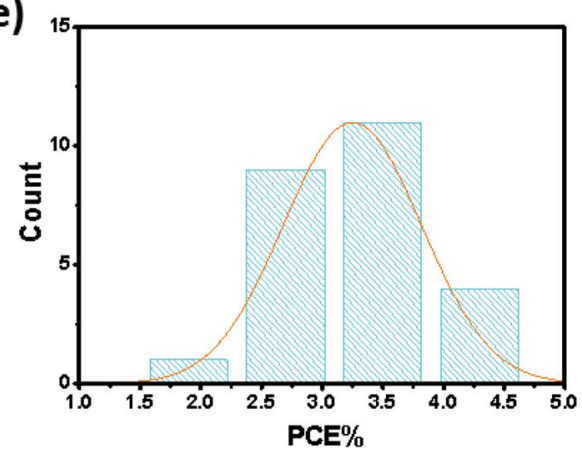

(b)

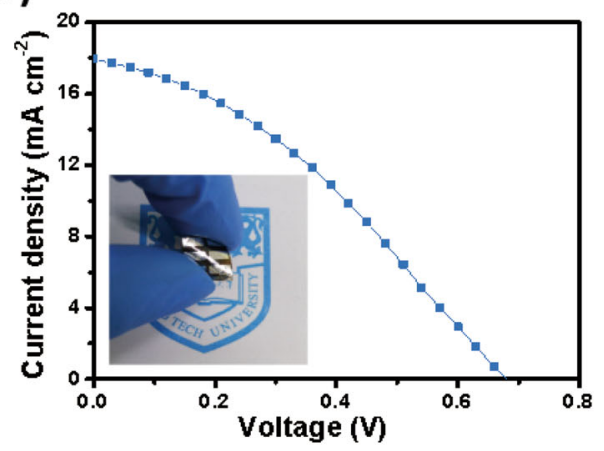

(d)

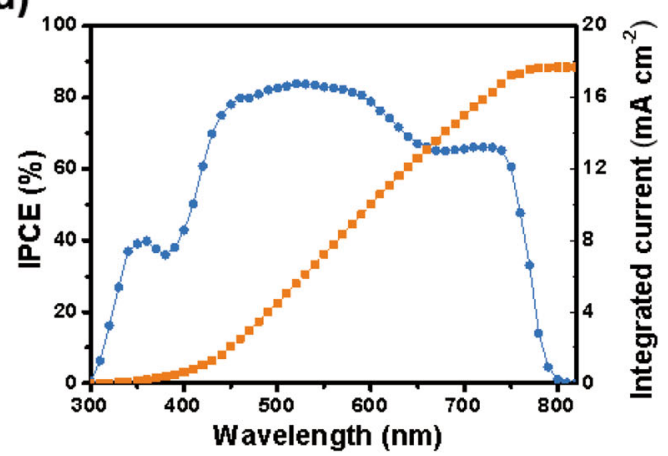

(f)

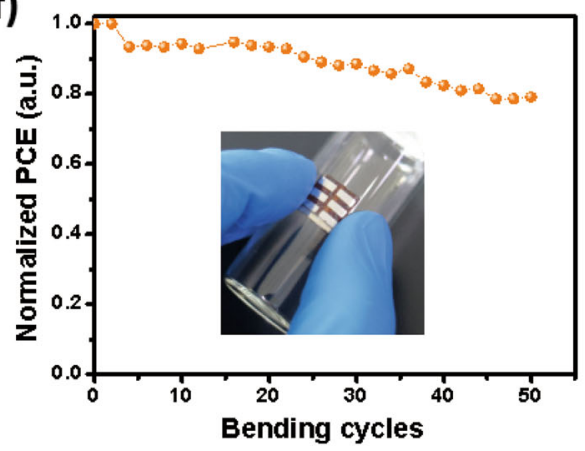

Fig. 4 Device performance of NCP-based PSCs. a The device structure of perovskite planar heterojunction solar cells. b Current densityvoltage (J-V) characterization of $\mathrm{MAPbl}_{3}$ devices. Inset: a digital photograph of NCP-based PSCs in bending state. c J-V curves under reverse and forward scanning directions. d IPCE of best-performing device and the integrated current densities obtained from the IPCE spectra. e PCE histogram of 25 devices fitted with a Gaussian distribution. f Normalized PCE-bending cycles characterization. Inset: a digital photograph of bending state by hand on a glass bottle with a diameter of $15 \mathrm{~mm}$

bending have shown better stability, more than $90 \%$ of the original PCE after 25 measurements (Supplementary Fig. 9), which also suggests that the efficiency decreasing is probably due to these cracks of perovskite layer rather than other factors (e.g., the humidity of environment). The PCE of NCP-based flexible PSCs was close to earlier value of flexible PSCs ( $6 \%$ on polymer substrate), ${ }^{37}$ nevertheless poor as compared to recent high-efficiency flexible

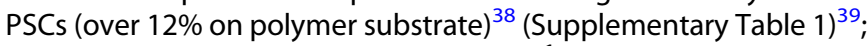
the power per weight reached $0.56 \mathrm{~W} \mathrm{~g}^{-1}$ due to the lightweight and thin NCP-based substrate, which was comparable to highperformance PSCs on ultrathin flexible substrate $\left(1.96 \mathrm{~W} \mathrm{~g}^{-1}\right){ }^{40}$ Some of these parameters were relatively low probably due to the poor electrical conductivity of transparent electrode made from doped PEDOT:PSS and the un-optimized preparation process of the PSCs. The performance of the NCP-based PSCs could be further improved by doping other materials (e.g., silver nanowires, graphene, carbon nanotubes, and other nano-materials) in transparent electrode and optimizing the preparation process (e.g., the spinning speed of spin-coating method, annealed temperature, and number of coating layer), which are underway.

Disposing of NCP-based PSCs

Because the main component of the PSCs (over $66 \mathrm{wt} \%$ in weight) is the NCP-based substrate, a cellulose-rich material that is very inflammable (Fig. 5f, g), the NCP-based PSCs can be easily disposed by flame burning within $3 \mathrm{~s}$ (Fig. $5 \mathrm{a}-\mathrm{d}$ ). The burnt ashes of NCP only include carbon materials, and the amount of the functional layers and electrodes is very minimal in these NCPbased PSCs, disposal of which generates little pollution to the environment. Based on these NCP-based substrates, we can build green flexible PSCs to address pressing energy issue and meanwhile alleviate "white pollution" by cutting down the usage of petroleum-based polymer substrates.

One remaining issue is the harmful lead used in the perovskite layer. As a heavy metal, lead is known to be a significant hazard to the environment and human health. ${ }^{41}$ We are working on new 
Table 1. Photovoltaic parameters of PSCs with $\mathrm{p}$-i-n configuration

\begin{tabular}{llllll}
\hline Device configuration & Scanning direction & $V_{\text {oc }}(\mathrm{V})$ & $J_{\mathrm{sc}}\left(\mathrm{mA} \mathrm{cm}^{-2}\right)$ & FF (\%) & PCE (\%) \\
\hline $\mathrm{p}$-i-n & Forward & $0.59 \pm 0.1$ & $16.46 \pm 1$ & $33.55 \pm 1.1$ & $3.25 \pm 1(4.25)$ \\
& Reverse & $0.51 \pm 0.1$ & $17.53 \pm 0.8$ & $36.63 \pm 1.2$ & $3.27 \pm 0.8(4.18)$ \\
\hline
\end{tabular}

NCP-based Pb-free PSCs. In this work, we have mainly focused on tackling the issue of the substrate by using NCP to replace petroleum-based polymers including PET. For example, PET will easily generate charred residue solid ash, black airborne particulate smoke, inhalable airborne particles, and toxic heavy metals during incineration. ${ }^{10}$ In addition, PSCs are usually disposed of through landfilling or incineration and incineration has a better environmental performance due to its recovery of energy and steam can offset the total environmental impact and meanwhile with the low amount of $\mathrm{Pb}$ recoverable from ashes. ${ }^{42}$

In summary, we report the first green flexible NCP-based PSCs, which may shed some light to current issues on energy and environmental pollution. This low-cost and biodegradable NCPbased substrate with coating of acrylic resin is also suitable for other functional devices, which can advance the development of flexible electronics. We will further optimize the functional layers and decrease the amount of potential toxic agent to prepare highperformance green flexible solar cells. The proposed recyclable concept will lead to a novel generation of more green flexible electronics.

\section{METHODS}

Materials

Cotton linter pulps (degree of polymerization $<500$, Hubei Jin Hanjiang, Jingmen, China) was used as raw material to prepare nanocellulose paper (NCP). The poly(3,4-ethylenedioxythiophene):poly(styrenesulfonic acid) (PEDOT:PSS) was purchased from Shanghai Han Feng Electronics, Shanghai, China. The [6,6]-phenyl C61-butyric acid methylester (PCBM) was purchased from Westwood Nano-C, Westwood, America. The acrylic resin particles (Methacrylic Acid Methyl Ester, analytical grade) were purchased from Damas-Beta Reagent Corp.. The part number is $89272 \mathrm{~A}$ and chemical formulations is $\left[\mathrm{CH}_{2} \mathrm{C}\left(\mathrm{CH}_{3}\right)\left(\mathrm{CO}_{2} \mathrm{CH}_{3}\right)\right] \mathrm{n}$. The silver nanoparticle inks (Jet-605C) were purchased from Suzhou KsHiSense, Suzhou, China. The other reagents and solvents including sodium hydroxide $(\mathrm{NaOH})$, urea, sulfuric acid $\left(\mathrm{H}_{2} \mathrm{SO}_{4}\right)$, ethylene glycol, dimethylformamide (DMF), acrylic resin particles, and Triton-X 100 were of analytical grade without further purification and purchased from Nanjing Wanqing Chemical Industry, Nanjing, China.

\section{Preparation of transparent NCP}

We prepared transparent NCP by using a solution containing alkali, urea and water to dissolve cotton at low temperature. ${ }^{43}$ In brief, a solution containing $\mathrm{NaOH} / \mathrm{urea} / \mathrm{H}_{2} \mathrm{O}$ with a weight ratio of 7:12:81 was pre-cooled to $-12{ }^{\circ} \mathrm{C}$. Then $4.00 \mathrm{~g}$ cotton linter pulps were put into $100 \mathrm{~mL}$ of this precooled solution to form viscous solution under vigorous mechanical stirring $(1000 \mathrm{rpm})$ for $2 \mathrm{~min}$ at room temperature. The viscous solution was centrifuged at $10,000 \mathrm{rpm}$ for $10 \mathrm{~min}$ and the clear upper solution was the nanocellulose solution for further use. The nanocellulose solution was spread on a glass plate by rod coating method ( $0.5 \mathrm{~mm}$ thick). The glass plate was immersed into a coagulation bath of $5 \mathrm{wt} \% \mathrm{H}_{2} \mathrm{SO}_{4}$. A sheet of hydrogel was formed after $5 \mathrm{~min}$, separated from the glass plate spontaneously. The hydrogel was thoroughly soaked in deionized water for $12 \mathrm{~h}$. Then the hydrogel was put on a substrate of PMMA to dry at room temperature for $48 \mathrm{~h}$ to form final transparent NCP. During the drying process, the sides of the hydrogel were attached to the PMMA by adhesive tapes to prevent shrinkage.

\section{Fabrication of waterproof NCP}

First $25.00 \mathrm{~g}$ of acrylic resin particles were dissolved in $100 \mathrm{~mL}$ of DMF to form $25 \mathrm{wt} \%$ viscous solution at ultrasonic condition. NCP $(6 \mathrm{~cm} \times 6 \mathrm{~cm})$ was dipped into the viscous solution of acrylic resin in glass dish for $5 \mathrm{~s}$.
Then NCP with viscous solution was put on a clean glass plate and glass rod was closely put over it. NCP and glass rod were pulled in opposite direction to remove redundant acrylic resin solution and make the viscous solution coat on the surface of NCP uniformly. Then the NCP coated with acrylic resin solution was cured at $90^{\circ} \mathrm{C}$ for $30 \mathrm{~min}$ to form NCP-based substrate. The NCP-based substrate was cleaned by deionized water, ethanol, and isopropanol in sequence prior to use.

\section{Construction of NCP-based PSCs}

The NCP-based substrate was cut into $1.3 \mathrm{~cm} \times 1.3 \mathrm{~cm}$ square sheets and attached to glass substrate by adhesive tape. The PEDOT:PSS (PH1000) doped with $6 \mathrm{v} \%$ ethylene glycol and $2 \mathrm{v} \%$ Triton-X 100 was spin-coated on NCP-based substrate as transparent anode and current collector. ${ }^{44}$ The PEDOT:PSS anode built at $1500 \mathrm{rpm}$ had low root-mean-square (RMS) surface roughness of $6.542 \mathrm{~nm}$ (Supplementary Fig. 3) and showed excellent transmittance $(90 \%)$, conductivity $(14.4 \mathrm{~K} \Omega / \mathrm{sq})$, bending ability at different angles (for 600 cycles), and outstanding stability for tape test (for 50 times) (Supplementary Fig. 5). In order to facilitate investigation of the NCP-based PSCs, silver nanoparticle ink (Supplementary Fig. 11a) was coated on one edge of PEDOT:PSS anode by direct-writing method with soft pen brush (Supplementary Fig. $11 \mathrm{~b}$ ) and annealed at $140^{\circ} \mathrm{C}$ for $10 \mathrm{~min}$ to form thin metal conductive layer and the thickness is $\sim 365 \mathrm{~nm}$ (Supplementary Fig. 11c).

The flexible PSCs were prepared on the NCP-based substrate based on the device structure of doped PEDOT:PSS anode $(40 \mathrm{~nm}) / \mathrm{PEDOT}$ :PSS 4083 $(30 \mathrm{~nm}) /$ perovskite $(350 \mathrm{~nm}) / \mathrm{PCBM}(100 \mathrm{~nm}) / \mathrm{Al}(100 \mathrm{~nm}) \cdot{ }^{45,46}$ As hole transport layer, the PEDOT:PSS 4083 was spin-coated on the doped PEDOT:PSS anode at $5000 \mathrm{rpm}$ for $50 \mathrm{~s}$ and annealed at $120^{\circ} \mathrm{C}$ for $30 \mathrm{~min}$. Herein, we used doped PEDOT:PSS PH1000 as bottom anode to facilitate charge-carrier transport and collection as its conductivity is highest in several PEDOT:PSS aqueous solutions. We used PEDOT:PSS 4083 as hole transport layer to balance charge-carrier mobility, the resistivity of which is very high $(500-5000 \Omega \mathrm{cm})$. The perovskite layer of $\mathrm{CH}_{3} \mathrm{NH}_{3} \mathrm{Pbl}_{3}\left(\mathrm{MAPbl}_{3}\right)$ was formed by a low-temperature one-step method and anti-solvent was used in the process (antisolvent engineering means that a solvent that does not dissolve the perovskite materials is dripped on the substrate during spinning and thereby promoting fast nucleation and growth of the crystals in the film). ${ }^{47}$ We chose chlorobenzene as an anti-solvent (Supplementary Fig. 10). The $\mathrm{CH}_{3} \mathrm{NH}_{3} \mathrm{l}(200 \mathrm{mg})$ was mixed with $\mathrm{Pbl}_{2}$ $(578 \mathrm{mg})$ in anhydrous $\mathrm{N}, \mathrm{N}$-dimethylformamide $(1 \mathrm{~mL})$ by shaking at $60^{\circ} \mathrm{C}$ for $1 \mathrm{~h}$ to produce a clear $\mathrm{CH}_{3} \mathrm{NH}_{3} \mathrm{Pbl}_{3}$ solution with concentration of $45 \mathrm{wt}$ $\%$. First, the $\mathrm{CH}_{3} \mathrm{NH}_{3} \mathrm{Pbl}_{3}$ solution was dropped onto the surface of PEDOT: PSS 4083. Then, the substrate was spun at $4000 \mathrm{rpm}$ for $30 \mathrm{~s}$. After $8 \mathrm{~s}$ of spinning, chlorobenzene was quickly dropped onto the substrate drop by drop (Supplementary Fig. 10,b). The obtained films were annealed at $100^{\circ} \mathrm{C}$ for $10 \mathrm{~min}^{47}$ (Supplementary Fig. 10,a). Perovskite layer of $\mathrm{CH}_{3} \mathrm{NH}_{3} \mathrm{Pbl}_{3}$ deposited on PEDOT:PSS 4083 showed good performance (Fig. 3d and Supplementary Fig. 8a). As electron transport layer, the PCBM was spin-coated on the perovskite at $1000 \mathrm{rpm}$ for $60 \mathrm{~s}$ and $2000 \mathrm{rpm}$ for $2 \mathrm{~s}$. Finally, the aluminum (Al) as cathode was deposited on the PCBM by vacuum evaporation at $1 \AA \mathrm{s}^{-1}$.

\section{Characterizations}

The RMS surface roughness of the NCP, NCP-based substrate and PEDOT: PSS anode was measured by atomic force microscope (XE-70, Park Corp.). The surface morphology of the NCP and NCP-based substrate was characterized by scanning electron microscope (JSM-7800F, JEOL Corp.). Contact angles of $2 \mu \mathrm{L}$ water droplets on the NCP, NCP-based substrate and pure acrylic resin film were measured by contact angle apparatus (DSA1005, KRUSS Corp.). The transparency of the NCP, NCP-based substrate and pure acrylic resin film was evaluated by UV-Vis spectrophotometer (UV-1750, SHIMADZU Corp.). The sheet resistance of the PEDOT:PSS anode was measured by a four-point probe instrument (ST2253, Suzhou Jingge Electronic Corp.). The NCP and NCP-based PSCs were measured by X-ray diffraction instrument (Smartlab-3KW, Rigaku 

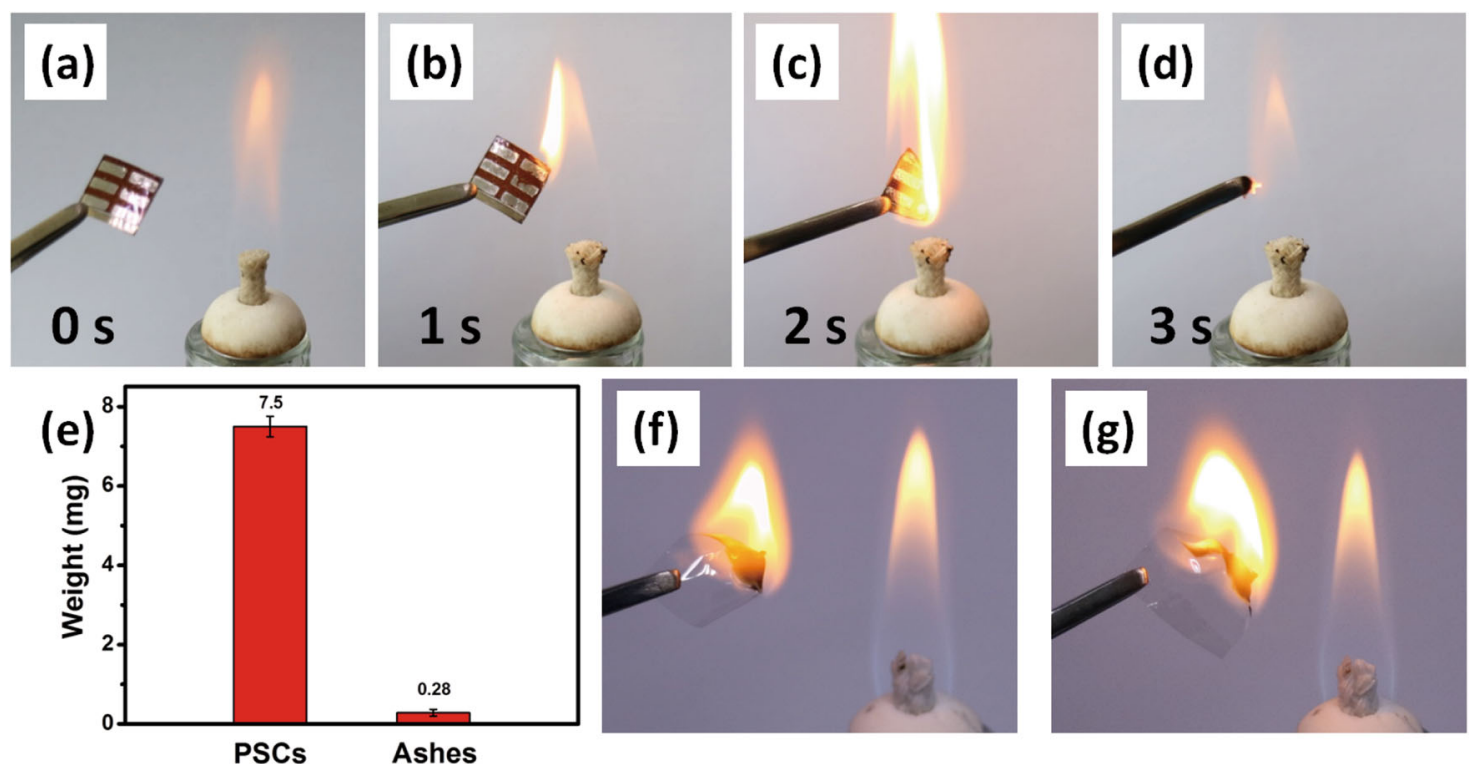

Fig. 5 The burning process of the NCP-based PSCs for a $0 \mathrm{~s}, \mathbf{b} 1 \mathrm{~s}, \mathbf{c} 2 \mathrm{~s}$, and d $3 \mathrm{~s}$. e The weight of the cell before and after incineration. Each data point is the mean of seven measurements. Digital photographs of $\mathbf{f}$ NCP and $\mathbf{g}$ NCP-based substrate with coating of acrylic resin being burnt by flame $(1.3 \mathrm{~cm} \times 1.3 \mathrm{~cm}$ square sheet $)$

Corp.). The coefficient of thermal expansion (CTE) of the NCP, NCP-based substrate and pure acrylic resin film $(50 \times 10 \times 0.04 \mathrm{~mm})$ was measured by a thermomechanical analyzer (TMA/402/F3, NETZSCH Corp.) with a heating rate of $5{ }^{\circ} \mathrm{C} / \mathrm{min}$ and $29 \mathrm{mN}$ tensile mode in $\mathrm{N}_{2}$ atmosphere. The CTE values were determined as the mean values of three measurements at $20-150^{\circ} \mathrm{C}$. The tensile strength of the NCP, NCP-based substrate and pure acrylic resin film $(50 \times 10 \times 0.04 \mathrm{~mm})$ was measured by a universal material testing machine (CM4202, Shenzhen SANS Company Corp.) with a tensile speed of $1 \mathrm{~mm} / \mathrm{min}$ at room temperature. The performance of the NCP-based PSCs was measured by an AM $1.5 \mathrm{G}\left(100 \mathrm{~mW} \mathrm{~cm}^{-2}\right)$ solar simulator (Enlitech SSF5-3A) equipped with a $450 \mathrm{~W}$ xenon lamp (TELIC) calibrated using standard $\mathrm{Si}$ photodiode. The light J-V curve was obtained through a Keithley 2400 source meter unit.

\section{DATA AVAILABILITY}

Data is available on request from the authors.

\section{ACKNOWLEDGEMENTS}

This work was financially supported by the National Natural Science Foundation of China (Grants 21675085, 51602149, 61705102, and 91733302), the National Key R\&D Program of China (Grant 2017YFA0204700), the National Basic Research Program of China, Fundamental Studies of Perovskite Solar Cells (Grant 2015CB932200), the Natural Science Foundation of Jiangsu Province for Distinguished Young Scholars (Grant BK20170042), the Natural Science Foundation of Jiangsu Province (Grants BK20161011 and BK20161010), Young 1000 Talents Global Recruitment Program of China, Jiangsu Specially-Appointed Professor Program, and "Six Talent Peaks" Project in Jiangsu Province, China.

\section{AUTHOR CONTRIBUTIONS}

L.G. and H.D.Y. designed the experiments and L.G. carried out the fabrication and characterization of NCP, NCP-based substrate, PEDOT:PSS anode. L.C. and Y.C. designed the architecture of NCP-based PSCs and L.C. carried out its preparation and characterization. M.H., J.L., Y.C., H.D.Y., and W.H. carried out the experimental validation and analysis of NCP-based PSCs. L.G., L.C., Y.C., H.D.Y., and W.H. wrote the paper. L.G. and L.C. contribute equally to the work.

\section{ADDITIONAL INFORMATION}

Supplementary information accompanies the paper on the npj Flexible Electronics website (https://doi.org/10.1038/s41528-019-0048-2).
Competing interests: The authors declare no competing interests.

Publisher's note: Springer Nature remains neutral with regard to jurisdictional claims in published maps and institutional affiliations.

\section{REFERENCES}

1. Lund, A. et al. Energy harvesting textiles for a rainy day: woven piezoelectrics based on melt-spun PVDF microfibres with a conducting core. npj Flex. Electron. 2, 1-9 (2018)

2. Wang, Z., Shi, Z., Li, T., Chen, Y. \& Huang, W. Stability of perovskite solar cells: a prospective on the substitution of the A cation and $\mathrm{X}$ anion. Angew. Chem. Int. Ed. 56, 1190-1212 (2017).

3. Wang, F., Bai, S., Tress, W., Hagfeldt, A. \& Gao, F. Defects engineering for highperformance perovskite solar cells. npj Flex. Electron. 2, 1-14 (2018).

4. Zhang, W. et al. Enhanced optoelectronic quality of perovskite thin films with hypophosphorous acid for planar heterojunction solar cells. Nat. Commun. 6, 1-9 (2015).

5. Liu, Z., You, P., Xie, C., Tang, G. \& Yan, F. Ultrathin and flexible perovskite solar cells with graphene transparent electrodes. Nano Energy 28, 151-157 (2016).

6. Roldán-Carmona, C. et al. Flexible high efficiency perovskite solar cells. Energy Environ. Sci. 7, 994-997 (2014).

7. $\mathrm{Hu}, \mathrm{W}$. et al. High-performance flexible photodetectors based on high-quality perovskite thin films by a vapor-solution method. Adv. Mater. 29, 1-8 (2017).

8. Di Giacomo, F., Fakharuddin, A., Jose, R. \& Brown, T. M. Progress, challenges and perspectives in flexible perovskite solar cells. Energy Environ. Sci. 9, 3007-3035 (2016).

9. Irimia-Vladu, M., Głowacki, E. D., Voss, G., Bauer, S. \& Sariciftci, N. S. Green and biodegradable electronics. Mater. Today 15, 340-346 (2012).

10. R. Jambeck, J. et al. Plastic waste inputs from land into the ocean. Science 347, 768-771 (2015).

11. Valavanidis, A., Iliopoulos, N., Gotsis, G. \& Fiotakis, K. Persistent free radicals, heavy metals and PAHs generated in particulate soot emissions and residue ash from controlled combustion of common types of plastic. J. Hazard. Mater. 156, 277-284 (2008).

12. Jung, Y. H. et al. High-performance green flexible electronics based on biodegradable cellulose nanofibril paper. Nat. Commun. 6, 1-11 (2015).

13. Lin, Y., Gritsenko, D., Liu, Q., Lu, X. \& Xu, J. Recent advancements in functionalized paper-based electronics. ACS Appl. Mater. Interfaces 8, 20501-20515 (2016).

14. Mahadeva, S. K., Walus, K. \& Stoeber, B. Paper as a platform for sensing applications and other devices: a review. ACS Appl. Mater. Interfaces 7, 8345-8362 (2015).

15. Zhang, Y. et al. Flexible electronics based on micro/nanostructured paper. Adv. Mater. 1801588, 1-39 (2018). 
16. Hamedi, M. M. et al. Integrating electronics and microfluidics on paper. Adv. Mater. 28, 5054-5063 (2016).

17. Ainla, A., Hamedi, M. M., Guder, F. \& Whitesides, G. M. Electrical textile valves for paper microfluidics. Adv. Mater. 29, 1-10 (2017)

18. Guder, F. et al. Paper-based electrical respiration sensor. Angew. Chem. Int. Ed. 55, 5727-5732 (2016)

19. Siegel, A. C. et al. Foldable printed circuit boards on paper substrates. Adv. Funct. Mater. 20, 28-35 (2010).

20. Castro-Hermosa, S., Dagar, J., Marsella, A. \& Brown, T. M. Perovskite solar cells on paper and the role of substrate and electrodes on performance. IEEE Electron Device Lett. 38, 1278-1281 (2017).

21. Xue, J., Song, F., Yin, X. W., Wang, X. L. \& Wang, Y. Z. Let it shine: a transparent and photoluminescent foldable nanocellulose/quantum dot paper. ACS Appl. Mater. Interfaces 7, 10076-10079 (2015).

22. Wang, S., Lu, A. \& Zhang, L. Recent advances in regenerated cellulose materials. Progress. Polym. Sci. 53, 169-206 (2016).

23. Nogi, M., Iwamoto, S., Nakagaito, A. N. \& Yano, H. Optically transparent nanofiber paper. Adv. Mater. 21, 1595-1598 (2009).

24. Zhang, J. et al. All-cellulose nanocomposites reinforced with in situ retained cellulose nanocrystals during selective dissolution of cellulose in an ionic liquid. ACS Sustain. Chem. Eng. 4, 4417-4423 (2016).

25. Zhu, H., Fang, Z., Preston, C., Li, Y. \& Hu, L. Transparent paper: fabrications, properties, and device applications. Energy Environ. Sci. 7, 269-287 (2014).

26. Zhang, Z., Wang, H., Li, S., Li, L. \& Li, D. Transparent and flexible cellulose nanofibers/silver nanowires/acrylic resin composite electrode. Compos. Part A 76, 309-315 (2015).

27. Park, N.-M. et al. Electroluminescent nanocellulose paper. Mater. Lett. 196, 12-15 (2017).

28. Devarayan, K., Lei, D., Kim, H.-Y. \& Kim, B.-S. Flexible transparent electrode based on PANi nanowire/nylon nanofiber reinforced cellulose acetate thin film as supercapacitor. Chem. Eng. J. 273, 603-609 (2015).

29. Wang, X. et al. Layer-by-layer assembled hybrid multilayer thin film electrodes based on transparent cellulose nanofibers paper for flexible supercapacitors applications. J. Power Sources 249, 148-155 (2014).

30. Zhu, H. et al. Extreme light management in mesoporous wood cellulose paper for optoelectronics. ACS Nano 10, 1369-1377 (2016).

31. $\mathrm{Hu}, \mathrm{L}$. et al. Transparent and conductive paper from nanocellulose fibers. Energy Environ. Sci. 6, 513-518 (2013).

32. Zhu, $\mathrm{H}$. et al. Biodegradable transparent substrates for flexible organic-lightemitting diodes. Energy Environ. Sci. 6, 2105-2111 (2013).

33. Daniele, M. A., Knight, A. J., Roberts, S. A., Radom, K. \& Erickson, J. S. Sweet substrate: a polysaccharide nanocomposite for conformal electronic decals. Adv. Mater. 27, 1600-1606 (2015).

34. Hsieh, M. C., Kim, C., Nogi, M. \& Suganuma, K. Electrically conductive lines on cellulose nanopaper for flexible electrical devices. Nanoscale 5, 9289-9295 (2013).

35. Fang, Z. et al. Highly transparent paper with tunable haze for green electronics. Energy Environ. Sci. 7, 3313-3319 (2014).
36. Zhu, H. et al. A gravure printed antenna on shape-stable transparent nanopaper. Nanoscale 6, 9110-9115 (2014).

37. Hoeng, F., Denneulin, A. \& Bras, J. Use of nanocellulose in printed electronics: a review. Nanoscale 8, 13131-13154 (2016).

38. Docampo, P., Ball, J. M., Darwich, M., Eperon, G. E. \& Snaith, H. J. Efficient organometal trihalide perovskite planar-heterojunction solar cells on flexible polymer substrates. Nat. Commun. 4, 1-6 (2013).

39. Kaltenbrunner, M. et al. Flexible high power-per-weight perovskite solar cells with chromium oxide-metal contacts for improved stability in air. Nat. Mater. 14, 1032-1039 (2015).

40. Poorkazem, K., Liu, D. \& L. Kelly, T. Fatigue resistance of a flexible, efficient, and metal oxide-free perovskite solar cell. J. Mater. Chem. A 3, 9241-9248 (2015).

41. Li, Y. et al. High-efficiency robust perovskite solar cells on ultrathin flexible substrates. Nat. Commun. 7, 1-10 (2016).

42. Binek, A. et al. Recycling perovskite solar cells to avoid lead waste. ACS Appl. Mater. Interfaces 8, 12881-12886 (2016).

43. Zhang, J., Gao, X., Deng, Y., Zha, Y. \& Yuan, C. Comparison of life cycle environmental impacts of different perovskite solar cell systems. Sol. Energy Mater. Sol. Cells 166, 9-17 (2017).

44. Yang, Q., Fukuzumi, H., Saito, T., Isogai, A. \& Zhang, L. Transparent cellulose films with high gas barrier properties fabricated from aqueous alkali/urea solutions. Biomacromolecules 12, 2766-2771 (2011).

45. Cheng, T., Zhang, Y.-Z., Zhang, J.-D., Lai, W.-Y. \& Huang, W. High-performance free-standing PEDOT:PSS electrodes for flexible and transparent all-solid-state supercapacitors. J. Mater. Chem. A 4, 10493-10499 (2016).

46. $\mathrm{Bi}, \mathrm{C}$. et al. Non-wetting surface-driven high-aspect-ratio crystalline grain growth for efficient hybrid perovskite solar cells. Nat. Commun. 6, 1-7 (2015).

47. Kim, H., Lim, K.-G. \& Lee, T.-W. Planar heterojunction organometal halide perovskite solar cells: roles of interfacial layers. Energy Environ. Sci. 9, 12-30 (2016).

48. Jeon, N. J. et al. Solvent engineering for high-performance inorganic-organic hybrid perovskite solar cells. Nat. Mater. 13, 897-903 (2014).

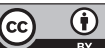

Open Access This article is licensed under a Creative Commons Attribution 4.0 International License, which permits use, sharing, adaptation, distribution and reproduction in any medium or format, as long as you give appropriate credit to the original author(s) and the source, provide a link to the Creative Commons license, and indicate if changes were made. The images or other third party material in this article are included in the article's Creative Commons license, unless indicated otherwise in a credit line to the material. If material is not included in the article's Creative Commons license and your intended use is not permitted by statutory regulation or exceeds the permitted use, you will need to obtain permission directly from the copyright holder. To view a copy of this license, visit http://creativecommons. org/licenses/by/4.0/.

(c) The Author(s) 2019 